\title{
Violência sexual contra crianças e adolescentes no campo da saúde e a intersetorialidade no sistema de garantias de direitos
}

\author{
Taiane Damasceno da Hora \\ Mestranda em Serviço Social pela Pontifícia Universidade Católica do Rio de Janeiro (PUC-RIO) \\ Graduação em Serviço Social pela Universidade Federal do Rio de Janeiro (UFRJ) \\ $\triangle$ thay.hora@gmail.com \\ Ariane Rego de Paiva \\ Professora do Departamento de Serviço Social da Pontifícia \\ Universidade Católica do Rio de Janeiro (PUC Rio) \\ $\triangle$ arianerpaiva77@hotmail.com
}

Recebido em 14 de agosto de 2017

Aceito em 09 de novembro de 2017

\section{Resumo:}

Este estudo retoma o debate que caracteriza a importância do campo da saúde pública para o atendimento e prevenção da violência sexual contra crianças e adolescentes e a necessária articulação intersetorial para garantir a integralidade da proteção social às vítimas. A partir de revisão bibliográfica e análise de documentos produzidos pela esfera federal, a primeira parte do trabalho apresenta a discussão teórica sobre diferentes concepções que norteiam o debate sobre a violência na sociedade brasileira. Em seguida, o estudo avança para a compreensão do conceito de violência sexual e suas tipologias e como o fenômeno afeta crianças e adolescentes. A terceira parte busca mostrar o avanço das regulações do Sistema Único de Saúde sobre a temática da violência sexual contra crianças e adolescentes nos setores primário, secundário e terciário, porém expressa a preocupação com a necessidade de aprofundamento dos estudos sobre a implementação efetiva dos serviços e como as unidades de saúde vêm consolidando a intersetorialidade, compreendida como a articulação entre saberes e práticas de diferentes setores e disciplinas das políticas públicas, principalmente em sua interseção com o sistema educacional e o Sistema Único de Assistência Social para coordenação e planejamento de ações complementares e integradas para garantir a proteção social desse público.

Palavras-chave: Saúde, Sistema de Garantias de Direitos, Violência Sexual, Intersetorialidade, Integralidade.

\section{Sexual violence against children and adolescents in the field of health and the intersectoriality in the system of guarantees of rights}

\begin{abstract}
:
This study resumes the debate that characterizes the importance of the field of public health for the care and prevention of sexual violence against children and adolescents and the necessary intersectoral articulation to guarantee the integrality of social protection to the victims. From bibliographical review and analysis of documents produced by the federal sphere, the first part of the paper presents the theoretical discussion about different conceptions that guide the debate on violence in Brazilian society. Next, the study advances towards understanding the concept of sexual violence and its typologies and how the phenomenon affects children and adolescents. The third part seeks to show the progress of the Unified Health System regulations on the issue of sexual
\end{abstract}


violence against children and adolescents in the primary, secondary and tertiary sectors, but expresses concern about the need of further studies on the effective implementation of services and how the health units are consolidating the intersectoriality, understood as the articulation between knowledge and practices of different sectors and disciplines of public policies, mainly in its intersection with the educational system and the Unified Social Assistance System for coordination and planning of complementary and integrated actions to ensure the social protection of this public. Keywords: Health, Rights Guarantees System, Sexual Violence, Intersectoriality, Integrality.

\section{Violencia sexual contra niños y adolescentes en el campo de la salud y la intersectorialidad en el sistema de garantías de derechos}

\section{Resumen:}

Este estudio retoma el debate que caracteriza la importancia del campo de la salud pública para la atención y prevención de la violencia sexual contra niños y adolescentes y la necesaria articulación intersectorial para garantizar la integralidad de la protección social a las víctimas. A partir de revisión bibliográfica y análisis de documentos producidos por la esfera federal, la primera parte del trabajo presenta la discusión teórica sobre diferentes concepciones que orientan el debate sobre la violencia en la sociedad brasileña. A continuación, el estudio avanza hacia la comprensión del concepto de violencia sexual y sus tipologías y cómo el fenómeno afecta a niños y adolescentes. La tercera parte busca mostrar el avance de las regulaciones del Sistema Único de Salud sobre la temática de la violencia sexual contra niños y adolescentes en los sectores primario, secundario y terciario, pero expresa la preocupación por la necesidad de profundizar los estudios sobre la implementación efectiva de los servicios y como las unidades de salud vienen consolidando la intersectorialidad, comprendida como la articulación entre saberes y prácticas de diferentes sectores y disciplinas de las políticas públicas, principalmente en su intersección con el sistema educativo y el Sistema Único de Asistencia Social para coordinación y planificación de acciones complementarias y integradas para garantizar la protección social de ese público.

Palabras clave: Salud, Sistema de Garantías de Derechos, Violencia Sexual, Intersectorialidad, Integralidad.

\section{INTRODUÇÃO}

O artigo $^{1}$ apresenta a discussão teórica sobre o atendimento da violência sexual de crianças e adolescentes na área da saúde, apresenta os principais marcos regulatórios que norteiam as ações dos serviços públicos de saúde e ressalta a necessidade de articulação com - Sistema de Garantia de Direitos (SGD), para assegurar a proteção integral conforme preconiza a legislação brasileira.

A metodologia utilizada para construção deste estudo foi o levantamento bibliográfico sobre o tema. Também foram utilizados dados do Sistema de Vigilância de

\footnotetext{
${ }^{1} \mathrm{O}$ estudo faz parte dos esforços de reflexão e sistematização da dissertação de mestrado em andamento no Programa de Pós-Graduação em Serviço Social na Pontifícia Universidade Católica do Rio de Janeiro (PUC-Rio).
} 
Violências e Acidentes (VIVA), do Disque 100 e do Censo SUAS, a fim de demonstrar a dimensão do fenômeno da violência sexual contra crianças e adolescentes no país e como são percebidas as ações intersetoriais nos atendimentos.

A violência sexual contra crianças e adolescentes é uma das formas históricas de violência contra esses segmentos no Brasil. Relaciona-se com o patriarcado e o machismo e com as relações desiguais de poder estabelecidas no processo de formação econômica, social e política brasileira. Como um fenômeno que se constitui atual na sociedade moderna capitalista, ele possui interlocução com os estudos sobre as expressões da "questão social" que afetam a sociedade e necessitam de intervenção do Estado e das políticas sociais no campo dos direitos e na construção de um patamar civilizatório que proteja com prioridade as crianças e adolescentes no país.

As políticas sociais, compreendidas como mediações na relação entre Estado e Sociedade no capitalismo, assumem o atendimento das expressões da "questão social" e das diferentes formas de desigualdade social, que ultrapassam as questões meramente econômicas, como é o caso da violência sexual contra crianças e adolescentes (IAMAMOTO, 2012; QUAGLIA et al, 2011). Para Quaglia et al. (2011) a violência sexual é uma das violações de direitos humanos fundamentais e dá visibilidade a uma violência estrutural da sociedade brasileira, que permeia as relações sociais em suas mais variadas esferas.

Entende-se que pela complexidade das questões que envolvem as diferentes formas de violência, esse não é um problema especifico da área da saúde e deve ser incluído na pauta de várias políticas sociais, porém, a violência coloca em risco o processo vital humano, visto que ameaça a vida, altera a saúde, produz enfermidade e resulta muitas vezes na morte das vítimas (MINAYO, 1994). Para Minayo (1994), a área da saúde tem como foco atender os efeitos da violência, como os traumas e as lesões físicas, nos serviços de emergência, na atenção especializada, nos processos de reabilitação, nos aspectos médicolegais e nos registros de informações.

Nota-se a dimensão do problema da violência contra crianças e adolescentes para a saúde no Brasil a partir dos dados apresentados pelo Sistema de Vigilância de Violências e 
Acidentes (VIVA)². No ano de 2013 foram registradas 29.784 notificações de violências contra crianças na idade de 0 a 9 anos. Entre essas, 13.867 eram meninos, enquanto 15.917 eram meninas. Ao analisar o tipo de violências nota-se que a violência sexual foi a terceira causa mais notificada $(28,4 \%)$. Em primeiro lugar está a negligência $(50,1 \%)$ e em segundo, a violência física $(28,6 \%)$.

Em relação ao segmento com idade entre 10 a 19 anos foram registradas 50.634 notificações. Sendo 17.886 do sexo masculino e 32.748 do sexo feminino. A violência sexual aparece como a segunda causa de notificações $(23,9 \%)$, em primeiro lugar está a agressão física $(63,3 \%)$ e em terceiro, a violência psicológica/moral $(23,0 \%)$.

Para as apresentações argumentativas deste estudo, o artigo foi dividido em três partes além da introdução e das considerações finais. A primeira parte apresenta a discussão teórica sobre diferentes concepções que norteiam o debate sobre a violência na sociedade brasileira. Em seguida, o estudo busca a compreensão do conceito de violência sexual e suas tipologias e como o fenômeno afeta crianças e adolescentes. A terceira parte busca mostrar o avanço das regulações do Sistema Único de Saúde sobre a temática da violência sexual contra crianças e adolescentes nos setores primário, secundário e terciário. Argumenta-se que tanto as unidades de atendimento da política de saúde, quanto as unidades de ensino da rede de educação e as unidades da assistência social vêm se consolidando para a organização da rede de prevenção e proteção de crianças e adolescentes e tornando os três sistemas, a Educação, o Sistema Único de Saúde (SUS) e Sistema Único de Assistência Social (SUAS), as principais referências para os serviços na garantia de direitos de crianças e adolescentes vitimados pela violência, o que impõe a necessidade de maior articulação e interseção nos desenhos institucionais entre as três políticas públicas, o que requer incorporar a intersetorialidade, compreendida como uma articulação de saberes e experiências (JUNQUEIRA, 1998), que ultrapassa o momento da execução, mas requer adotá-la como um mecanismo de articulação no planejamento, nos processos de formulação conjunta, no monitoramento e na avaliação, como processos constituintes da proteção social de crianças e adolescentes.

\footnotetext{
${ }^{2}$ O Sistema de Vigilância de Violências e Acidentes (Viva) foi implantado em 2006 com o objetivo de coletar dados e gerar informações sobre violências e acidentes para subsidiar políticas em saúde pública direcionadas a esses agravos, buscando preveni-los. (BRASIL, 2013, p.17).
} 


\section{VIOLÊNCIA E SUAS PARTICULARIDADES SÓCIO-HISTÓRICAS NO BRASIL}

Segundo Minayo (2006), a violência é um fenômeno social que possui múltiplas causas. A palavra violência tem origem no latim e significa força, refere-se a ações de constrangimento e uso da superioridade física sobre o outro. A violência está ligada a conflitos de autoridade, lutas pelo poder e vontade de posse. Ela varia conforme a época e o lugar.

Há certa dificuldade em conceituar violência, pois, de acordo com Minayo (2006), se trata de um fenômeno da ordem do vivido, suas manifestações provocam ou são provocadas por uma forte carga emocional de quem a comete, de quem a sofre e de quem a presencia. A OMS (2002) define violência como

Uso intencional da força física ou do poder, real ou em ameaça, contra si próprio, contra outra pessoa, ou contra um grupo ou uma comunidade, que resulte ou tenha grande possibilidade de resultar em lesão, morte, dano psicológico, deficiência de desenvolvimento ou privação (OMS, 2002, p.4).

Segundo a resolução WHA 49.25 da World Health Assembly de 1996, a violência é definida a partir de três categorias, que fazem referência ao indivíduo que a praticou. Essas são definidas como: violência auto infligida, dividida em pensamento suicida e auto abuso; violência interpessoal, subdividida em violência da família ou de parceiro íntimo e comunitário; e violência coletiva, subdividida em violência social, política e econômica (OMS, 2002). Os atos violentos podem ser de natureza física, sexual, psicológica e negligência. Esses tipos de violência se materializam dentro das categorias e das subcategorias apresentadas anteriormente, com exceção da violência auto infligida (OMS, 2002).

Para alguns autores, como Minayo (2006), a violência no Brasil pode ser considerada estrutural e 'estruturante', pois está enraizada na sociedade, ela tem relação com o grau elevadíssimo de desigualdade, que é histórico. Essas desigualdades ultrapassam a esfera econômica, ganhando outras dimensões. Existem diferentes abordagens para compreensão e explicação sobre o fenômeno da violência, o que implica em diferentes aportes teóricometodológicos para seu estudo. 
Velho (2000) traz uma análise da violência na sociedade brasileira, afirmando que ela tem relação com as desigualdades sociais, entretanto não pode ser restrita a isso. É necessário compreender que há também uma perda de referenciais éticos na sociedade, esses são a base para as interações entre os indivíduos e grupos. Essa perda de referenciais éticos fica mais evidente com a modernização das grandes cidades que modifica o sistema de valores da sociedade. Para esse autor, na sociedade brasileira tradicional as relações eram baseadas em ações de reciprocidade. Com o fim dessa sociedade a modernização ganha destaque. Um dos resultados dessa mudança é o crescimento das grandes cidades, passando a influenciar nos sistemas de valores e nas relações sociais dentro da sociedade.

Velho (2004) sinaliza que suas afirmações não têm como intuito defender a sociedade tradicional. Ele busca colocar em evidência que no Brasil e em outros lugares do mundo as mudanças que ocorrem durante a transição de uma sociedade tradicional para a modernidade afetaram os valores da sociedade, chamando atenção para a reciprocidade. Para o autor, a tensão social sempre existiu, porém as formas de resolução eram diferentes e buscavam evitar os conflitos físicos. Outro fator que implica no aumento da violência é a ausência de direitos, uma vez que, em geral, as camadas populares são privadas do acesso a bens e valores. Esse problema acaba acirrando a tensão e ódio na sociedade.

Para Adorno (2004), a violência na sociedade brasileira possui reflexos das duas décadas que o país viveu sob o regime militar (1964-1985). o país caminha em passos lentos para algumas mudanças vislumbradas no processo democrático, como a ampliação de espaços de participação social efetivos, que signifiquem alteração na representatividade política, bem como a lentidão para o alargamento dos direitos.

Mesmo com as mudanças na sociedade, persistem graves formas de violação de direitos humanos, produto de uma violência endêmica, que ocorre de forma naturalizada no Brasil. O controle legal da violência não se concretizou e, mesmo em um regime democrático, prevaleceu um aprofundamento da cultura autoritária, que ressurge frequentemente em diferentes formas de comportamentos, sejam eles políticos, institucionais e nos microprocessos sociais, essas alimentam as formas de violência social, o patrimonialismo e o clientelismo. Alguns fatores explicam essa não concretização do controle da violência, como por exemplo, o restrito raio de ação dos grupos organizados da 
sociedade civil; a impunidade dos agressores; e a ausência de efetivo controle do aparato repressivo do poder civil (ADORNO, 1995; MINAYO, 2006).

Chauí apresenta uma discussão da violência relacionado-a com a ética. Para a autora a violência contrapõe-se à ética, pois [...] "trata seres racionais e sensíveis, dotados de linguagem e de liberdade como se fossem coisas, isto é, irracionais, incessiviveis, mudos, inertes ou passivos" (CHAUÍ, 2011, p.379). Esse ser é tratado como um não humano. Ainda nessa linha de pensamento, a autora afirma que atualmente fala-se em um retorno à ética ou na necessidade de ter ética devido à crise de valores. Nesse pensamento, a ética ganha um status de coisa e podemos aproximar as discussões dessa autora como um contraponto às ideias de Velho, já apresentadas anteriormente.

Chauí (2011) sinaliza algumas formas de pensar a ética, à qual se deseja retornar. Em primeiro lugar, a ética é definida como uma reforma dos costumes, por isso possui nexos na moralidade. Trata-se de retornar a valores, excluindo qualquer forma de análise das condições presentes de uma ação ética. Em segundo lugar, a ética é confundida com a organização, divisão de funções e responsabilidades numa instituição, ou seja, é compreendida como um código de ações predefinidas em conformidade com os objetivos de uma instituição. Em terceiro lugar, a ética é relacionada com a defesa humanitária dos direitos humanos contra violência. Para Chauí (2011), esses pensamentos transformam a ética em uma simples ideologia. Segundo a autora, no Brasil permanece um:

[...] mito poderoso, o da não violência brasileira, isto é a imagem de um povo generoso, alegre, sensual, solidário, que desconhece o racismo, o sexismo, o machismo, que respeita as dificuldades étnicas, religiosas e políticas, não discrimina as pessoas por suas escolhas sexuais etc. (CHAUİ, 2011, p.381).

Subsistem alguns mecanismos ideológicos de conservação desse mito. 0 primeiro é o mito da exclusão. Segundo Chauí (2011), afirma-se que a nação brasileira não é violenta, logo a violência é uma prática de gente que não faz parte da nação. O segundo mecanismo está baseado na afirmação de que a violência é acidental, seria um acontecimento que se materializa somente em alguns momentos e em determinados espaços. No terceiro mecanismo, a violência está delimitada no campo da delinquência e da criminalidade. 0 crime estaria restringido aos ataques à propriedade privada. Nesse mecanismo, são determinados os agentes violentos, prioritariamente os pobres, e, por consequência, há o 
favorecimento de ações como a da polícia contra o pobre, negro, crianças em situação de rua e moradores das favelas. Por hora há uma condenação às ações da polícia quando há práticas como chacina, mas em outros momentos acaba-se por naturalizá-las.

O quarto mecanismo apresentado por Chauí (2011) coloca a violência como um problema da modernidade, sendo uma questão que tem relação com a migração da população do campo para cidade e de regiões mais pobres para as mais ricas. Logo, esse fenômeno da migração seria o motivador temporário, cujos principais públicos são os pobres e desadaptados. Trata-se de um mecanismo sociológico. O último mecanismo, e que merece destaque, é o da inversão do real, esse coloca ideias e valores violentos como se fossem não violentos. Como um dos exemplos pode-se citar violências como o machismo entendido como uma forma de proteção à mulher e justifica questões como o estupro, culpabilizando a mulher.

Cabe ressaltar que historicamente a sociedade brasileira foi formada por um processo baseado na violência, de forma velada, em que o colonizador português impõe um modelo patriarcal, promovendo uma mistura de raças, agricultura e escravidão. 0 sistema patriarcal ultrapassa a esfera familiar e influência também outras instituições políticas no Brasil. A sociedade brasileira foi organizada pelo patriarcado, com um poder centrado na família e na Igreja. Logo, as demais instituições, como aponta Lapa (1999), ficam sujeitas a esse domínio patriarcal.

A aparente harmonia social no país teria sido resultante da miscigenação entre negros, índios e portugueses - mito da democracia racial. No entanto, essa miscigenação ocorreu por motivos sociais, políticos e econômicos, e com práticas de extrema violência. Essa miscigenação destruiu, através dos valores culturais trazidos por Portugal e outras partes da Europa, a cultura daqueles que viviam no Brasil. Os portugueses chegam ao Brasil habitado por uma raça considerada atrasada e se colocam como uma cultura dominadora, que dissolve a cultura nativa (BASTOS, 1999; LAPA, 1999; VAINFAS, 2001).

A violência é um fenômeno multicausal, portanto não pode ser restrita a um único fator. Deve ser compreendida como um fenômeno social que vai além das questões de desigualdades sociais e econômicas, ela possui outras dimensões que variam conforme a organização de cada sociedade. Atualmente, a violência adquiriu um caráter endêmico, 
complementando ainda mais a necessidade da atenção na saúde (MINAYO, 2005). Discutiremos a seguir de que formas se apresentam a violência sexual contra crianças e adolescentes e os atendimentos no campo da saúde no Brasil.

\section{VIOLÊNCIA SEXUAL CONTRA CRIANÇAS E ADOLESCENTES: DEFINIÇÃO DE CONCEITOS E DISCUSSÃO NO CAMPO DA SAÚDE}

Na década de 1980, profissionais da saúde como médicos, pesquisadores e os sistemas de saúde pública passaram a se dedicar a compreender as raízes da violência e discutir medidas para sua prevenção. É também nessa década que a violência passa a ser considerada um problema de saúde pública, devido ao aumento de mortes e traumas que congestionam os serviços de saúde (DESLANDES, 1994; DAHLBERG e KRUG, 2007).

Na década de 1990, a violência passa a ser uma preocupação mundial, ganhando destaque na OMS, passando a fazer parte da agenda de intervenções. Em 1993, foi instituído o Dia Mundial da Saúde, com o objetivo de comemorar a "Prevenção de Acidentes e Traumatismo" (KRUG et al. 2002; MINAYO, 1994). Em 1996, com a 49ª Assembleia Mundial de Saúde, foi adotada a Resolução 49.25 da World Health Assembly de 1996, declarando que a violência é um problema também da saúde pública. Nessa assembleia foi ressaltada a importância da compreensão desse fenômeno social para a saúde e quais as consequências em curto e longo prazos para as vítimas.

O tema violência contra crianças e adolescentes foi um dos pioneiros levantados com o intuito de sensibilizar sobre a relação entre violência e saúde. Nos anos 1960, os profissionais da saúde começaram a fazer um número significativo de denúncias sobre as diversas formas de violência contra crianças e adolescentes e como esse problema influenciaria no crescimento e desenvolvimento das vítimas (MINAYO, 2006).

No nível internacional, a violência contra crianças e adolescentes é uma realidade que começou a ser entendida como um problema que necessita da intervenção do setor saúde no século XX, tendo como principais protagonistas pediatras e sanitaristas (MINAYO; SANCHEZ, 2006). Segundo Silva (2002), os pediatras norte-americanos Kempe e Kempe, foram os primeiros profissionais a evidenciar o fenômeno da violência contra crianças 
durante o atendimento médico. Uma das principais descobertas desses pediatras foi denominada como "Síndrome da Criança Espancada" e teve como resultado uma campanha norte-americana chamando atenção para a necessidade de proteção das crianças e adolescentes.

Azevedo e Guerra (2009) afirmam que com a descoberta da "Síndrome da Criança Espancada", os profissionais da área médica assumiram a hegemonia desse fenômeno. Somente no inicio da década de 1970 resgata-se as contribuições de outras áreas de conhecimento como da psicologia, direito, sociologia, antropologia e etc, colocando assim um fim à hegemonia médica.

Sobre o termo violência sexual, Faleiros (2000) afirma que é uma categoria que serve para explicar a vitimização sexual, ela está relacionada com o processo baseado nas relações de poder em que ocorre o abuso sexual. Já o abuso sexual é definido como a situação onde ocorre o uso excessivo, nesse há uma ultrapassagem de limites que afeta os direitos das vítimas de diversas formas. Segundo Faleiros (2000), o termo abuso sexual classifica as situações de violência sexual contra crianças e adolescentes e dá ênfase principalmente aos casos que dizem respeito a violência intrafamiliar ou abuso sexual doméstico.

O abuso sexual, segundo Habigzang et al. (2005), pode ser definido como qualquer ato de contato ou interação entre uma criança ou adolescente e alguém em estágio de desenvolvimento psicossexual mais avançado, em uma relação em que crianças e adolescentes estiverem sendo usados para estimulação sexual do perpetrador. 0 abuso sexual inclui uma relação de poder entre os adultos e as crianças, englobando situações diversas que vão desde carícias, manipulação da genitália, mama, anus, exploração sexual, pornografia, contato físico, voyerismo, assédio, exibicionismo, e o ato sexual com ou sem penetração (ABRAPIA, 2002; HABIGZANG et al., 2005). Esse tipo de violência contra crianças e adolescentes ocorre no ambiente doméstico e familiar e também fora dele.

Devido a suas ligações afetivas, a família deveria ser uma instituição voltada para garantir a proteção para os membros que são considerados vulneráveis. Porém, é no contexto familiar e doméstico que mais ocorrem violências. Tal fato vem se perpetuando ao longo dos anos e acontecendo de forma silenciosa, pois a família é compreendida como uma 
instituição sagrada intocável, assim, sempre se busca evitar sua exposição (SAFFIOTI, 2004; DAY et al., 2003).

Sobre a violência doméstica, Day et al. (2003) afirmam que a terminologia doméstica inclui as pessoas que convivem no ambiente familiar como os empregados, agregados e até mesmo visitantes, ou seja, todos que estão no espaço doméstico - espaço físico e também simbólico, que se estende para fora do lar.

Para Saffioti (2004), a violência contra crianças e adolescentes se materializa também na forma de violência intrafamiliar, que, segundo a autora, pode ocorrer dentro do domicilio, mas não está restrita apenas ao espaço físico do lar. Sua peculiaridade é o fato de ser praticada por membros da família, incluindo aqueles com laços afetivos, e determina os padrões de relacionamento abusivos entre os membros de uma família.

Oliveira (2012) afirma que o abuso sexual contra crianças e adolescentes pode ser conceituado também como uma "Síndrome de Segredo", em relação às vitimas e seus familiares. Essa questão do segredo envolve uma série de questões como censura, vergonha, autocrítica, rejeição, medo de perder os vínculos familiares e outras questões que envolvem o equilíbrio familiar.

A violência sexual contra crianças e adolescentes é uma problemática que adquire caráter endêmico, tornando-se um problema de saúde pública na medida em que as vítimas ficam suscetíveis a lesões físicas, distúrbios sexuais, uso de drogas, prostituição, depressão e suicídios. Além disso, existem os riscos de adquirir doenças sexualmente transmissíveis, como a Síndrome da Imunodeficiência Adquirida (HIV), e a gravidez indesejada (RIBEIRO, FERRIANI, REIS, 2004).

Entre as políticas sociais e serviços públicos, o campo da saúde é o que mais absorve crianças e adolescentes vítimas de violência sexual, ressaltando que ainda existe o problema da subnotificação, fato que interfere diretamente na quantificação de dados e compreensão da dimensão do problema (DESLANDES; VIEIRA; CAVALCANTI; SILVA, 2016).

No que diz respeito às normatizações sobre violência sexual na área da saúde, no final dos anos 1990, o Ministério da Saúde (MS), pressionado pelo movimento feminista e pelas entidades nacionais e internacionais voltadas para a garantia de direitos humanos,

\footnotetext{
${ }^{3}$ Conceito utilizado por Furniss (1993).
} 
implementou algumas políticas e definiu ações para prevenção e tratamento dos agravos resultantes da violência sexual. Para tanto, foi elaborada a Norma Técnica de Prevenção e Tratamento dos Agravos Resultantes da Violência Sexual contra Mulheres e Adolescentes (DESLANDES, LIMA, 2011). A primeira versão dessa norma técnica foi elaborada em 1998 e em 2005 foi atualizada pela área técnica de Saúde da Mulher, do Ministério da Saúde. Essa atualização buscou organizar a assistência às vítimas de violência sexual nos serviços públicos de saúde e normatizar o atendimento clínico, a contracepção de emergência e a profilaxia de doenças, além do apoio psicológico e social (DESLANDES, LIMA, 2011).

Para Paixão (2011), as versões de 2005 e, posteriormente, de 2010 da Norma Técnica trazem questões importantes sobre o atendimento desse público como: o acolhimento, o aborto legal, o detalhamento dos tipos de doses e os efeitos adversos de drogas que devem ser administrados nos casos de Doenças Sexualmente Transmissíveis (DSTs) ou na profilaxia de HIV/AIDS e o detalhamento das fichas de registros. Outra questão relevante sobre esse documento é que, a partir da revisão de 2005, a criança passa a ser mencionada. No entanto, mesmo com os avanços, esse documento ainda não trouxe uma abordagem sobre o atendimento do público masculino e casos de violências crônicas.

Em 2010, a Secretaria de Atenção à Saúde, especificamente o Departamento de Ações Programáticas Estratégicas do Ministério da Saúde, elaborou a Linha de Cuidado para Atenção Integral à Saúde de Crianças, Adolescentes e suas Famílias em Situação de Violências - Orientação para Gestores e Profissionais de Saúde. Esse documento trata de uma estratégia para a ação e busca cumprir o princípio da atenção integral à saúde, e tem como alvo a articulação do cuidado desde a atenção primária até os níveis mais complexos de atenção. O documento traz também uma questão importante que é a interação dos demais sistemas para garantir os direitos, proteção e defesa de crianças e adolescentes (MINISTÉRIO DA SAÚDE, 2010).

A linha de cuidados é um documento organizado de forma pedagógica que traz questões relevantes como o estímulo para os profissionais desenvolverem ações de prevenção a violências, promoção da saúde e cultura da paz. Busca enfatizar o trabalho junto às famílias e também orienta os profissionais de saúde sobre a identificação de sinais e sintomas de violência. Esse documento traz também uma ênfase importante sobre a questão da articulação da rede de proteção social existente no território. 
No campo da violência exige-se um trabalho que seja realizado em rede, que se materializa "[...] de forma articulada, baseado na solidariedade e na cooperação entre organizações que, por meio da articulação política, negociam e partilham recursos de acordo com os interesses e necessidades" (MINISTÉRIO DA SÁUDE, 2010, p.77).

$\mathrm{O}$ atendimento para crianças e adolescentes vítimas de violência sexual nos serviços de saúde, segundo os documentos, deve compreender dimensões como o acolhimento, momento em que a criança ou o adolescente é recebida/o no serviço de saúde e são realizados os encaminhamentos necessários para a rede de cuidados e proteção social; o atendimento, em que são realizadas consultas clínicas, anamnese, exames físicos e é feito o planejamento para o tratamento, a profilaxia de doenças, a avaliação psicológica e etc. A notificação faz parte do processo de atendimento, o profissional deve preencher a ficha de notificação, encaminha-la para o Sistema de Vigilância de Violência e Acidentes (Viva) da Secretaria Municipal de Saúde e também é preciso fazer o comunicado ao Conselho Tutelar e acionar outros órgãos competentes quando necessário, por exemplo, o Ministério Publico em casos de interrupção da gravidez.

A violência não é um problema específico do campo da saúde, portanto, torna-se necessário que outros serviços dentro do território sejam mobilizados. As normatizações chamam atenção para o estabelecimento de fluxo referenciado, o diálogo permanente, e a troca de informações com todos os serviços que são disponibilizados no município e também nos municípios vizinhos, o que se estabelece com a intersetorialidade. A atuação da saúde pública nos casos de violência requer também uma ação interdisciplinar, ou seja, fundamentada no conhecimento das diversas disciplinas. Além da interdisciplinaridade, também há grande ênfase nas ações de saúde coletiva, que são compostas por vários setores como serviços sociais, saúde, educação e justiça. Diante disso, é possível superar a velha premissa de que os problemas de saúde eram apenas uma demanda a ser resolvida pelos médicos, que eram os profissionais que possuíam maior status na saúde. Logo, cada área tem um papel importante na atuação com a violência, que é definida como um agravo à saúde (OMS, 2002). 


\section{INTERSETORIALIDADE E O SISTEMA DE GARANTIAS DE DIREITOS PARA PROTEÇÃO DE CRIANÇAS E ADOLESCENTES}

O Brasil possui uma das legislações mais avançadas do mundo no que tange à proteção de crianças e adolescentes. Seguindo as orientações de organismos e tratados internacionais, através da Constituição Federal de 1988, a família passou a ser definida como um espaço de proteção social, dando assim um passo importante no reconhecimento da necessidade de se proteger as crianças e adolescentes, que são compreendidos como seres em desenvolvimento que precisam de cuidados especiais. A responsabilidade do cuidado passa a ser atribuída ao Estado, dando um passo importante para o fim de sua ausência.

No ano de 1990, o Brasil ratificou a Convenção dos Direitos da Criança da Organização das Nações Unidas e, nesse mesmo ano, foi criado o Estatuto da Criança e do Adolescente (ECA), Lei 8.069, de 13 de julho de 1990. Passa-se, a partir desse período, a assumir o que os estudiosos denominaram de doutrina da proteção integral, que parte da compreensão de que crianças e adolescentes são cidadãos plenos, sujeitos à proteção prioritária, tratando-se de pessoas em desenvolvimento. Com o ECA, a violência contra criança e adolescente ganha visibilidade na legislação e, logo, deve ser combatida e também passa a ser definida como um problema de saúde, nessa lei são estabelecidos os Direitos Fundamentais e o Direito à Vida e à Saúde (BEZERRA, 2006).

Segundo Farineli e Pierini (2016), o ECA consolida o Direito à Proteção Integral a Crianças e Adolescentes, trazendo a necessidade da existência de uma rede que integre o Sistema de Garantias de Direitos da Criança e do Adolescente (SGDCA). Trata-se de um sistema estratégico, para além de um sistema de atendimento, complexo em sua estruturação, que deve promover ações que viabilizem a prioridade do atendimento à infância em qualquer situação (FARINELI; PIERINI, 2016, p.63). Os órgãos públicos e as organizações da sociedade civil devem exercer suas funções, organizando-se em rede, isso se materializa através dos três eixos estabelecidos na SGDCA: Defesa dos direitos humanos; Promoção dos direitos humanos; e Controle da efetivação dos direitos humanos.

O eixo de defesa dos direitos humanos é caracterizado pela garantia de acesso à justiça. Estão incluídos aqui órgãos públicos judiciais, Ministério Público, Procuradorias Gerais de Justiça, Defensorias Públicas; Advocacia Geral da União e as Procuradorias Gerais 
dos estados; Polícias; Conselhos Tutelares; Ouvidorias e entidades de defesa de direitos humanos incumbidas de prestar proteção jurídico-social (CONANDA, 2006).

O segundo eixo é o de Promoção de direitos humanos, que concretiza-se através do desenvolvimento da política de atendimento dos direitos das crianças e dos adolescentes. Sobre seu desenvolvimento, ocorre de forma transversal e intersetorial, articulando todas as políticas públicas. Suas ações são voltadas para favorecer a garantia integral dos direitos de crianças e adolescentes (CONANDA, 2006).

O terceiro e último eixo, denominado de Controle da efetivação dos direitos humanos, trata do controle das ações públicas de promoção e da defesa dos direitos humanos das crianças e adolescentes. Para tanto, deve ser feito a partir de instâncias colegiadas próprias. É preciso também assegurar a paridade de participação dos órgãos governamentais e entidades sociais que são classificadas como: conselhos dos direitos de crianças e adolescentes; conselhos setoriais de formulação e controle de políticas públicas; e os órgãos e os poderes de controle interno e externo (CONANDA, 2006).

Atualmente os principais serviços da rede e órgãos de proteção aos direitos de crianças e adolescentes que compõe o SGDA são: Disque - Denúncia, Conselho Tutelar, Delegacia especializada, Ministério Público, Defensoria Pública e Justiça da Infância e Juventude (SECRETARIA DE DIREITOS HUMANOS, 2011).

Segundo os dados do Disque $100^{4}$, em 2015 foram realizadas 17.583 (11\%) denúncias de violência sexual e em 2016, notificou-se 15.707 (10,9\%) casos. A violência sexual aparece, nesse período, como o quarto tipo de violência que mais foi denunciada. Em primeiro lugar aparece a negligência, em segundo, a violência psicológica e em terceiro, a violência física. No Rio de Janeiro, em 2015, contabilizou-se um total de 1.226 denúncias de abuso sexual contra crianças e adolescentes e em 2016, esses números sofreram uma redução, 926 denúncias. Os principais encaminhamentos foram realizados para as seguintes instituições: Ministério Público (74.275); Conselho Tutelar (72.738); Delegacia de Polícia (10.838); Delegacia de Proteção à Criança e ao Adolescente (5.827); Ouvidorias (3.314) e outros serviços (8.794).

\footnotetext{
4 O Disque 100 é um canal de comunicação da Ouvidoria de Direitos Humanos, trata-se de um serviço de atendimento telefônico, que funciona gratuitamente a fim de receber demandas referentes à violação de direitos humanos, funciona 24 horas e semanalmente em território nacional. Conta também com serviços de internet como a Ouvidoria Online, Clique 100 e com o aplicativo Proteja Brasil.
} 
O SGDCA tem como medida estabelecer uma articulação com todos os sistemas nacionais de operacionalização de políticas públicas, assim engloba as áreas das políticas sociais de saúde, educação e assistência social. Além disso, também estão incluídas outras políticas como a de trabalho, segurança pública, planejamento, orçamentária, relações exteriores e promoção da igualdade e valorização da diversidade (CONANDA, 2006). Nos últimos anos, as políticas de Educação e Assistência Social têm promovido projetos e serviços com visibilidade para a questão da violência sexual contra crianças e adolescentes e que protagonizam, junto com os serviços na área de saúde, uma verdadeira rede de promoção e que precisam estar articulados e devidamente divulgados nos municípios. Chamamos atenção para os projetos desenvolvidos pelas escolas e pelas unidades da assistência social, os Centros de Referência de Assistência Social (CRAS), os Centros de Referências Especializados de Assistência Social (CREAS), além de serviços de acolhimento, como abrigos e Família Acolhedora.

Através do Sistema Único de Assistência Social (SUAS), desde 2005 foram criados serviços continuados em todo o território nacional, que atendem as famílias e apoiam-nas em situações de violação de direitos, incluindo as diversas formas de violência. O Serviço de Proteção Integral à Família (PAIF) e o Serviço de Convivência e Fortalecimento de Vínculos (SCFV) são serviços ofertados nos CRAS, com propostas mais abrangentes, destinados à proteção e prevenção das violências. O serviço de Proteção e Atendimento Especializado a Famílias e Indivíduos (PAEFI), é direcionado aos que se encontram em situações de violência e violação de direitos e é executado nos CREAS.

Nos dados nacionais retirados do Censo SUAS 2016 (MDS, 2016), identificou-se que 2.464 CREAS, nas cinco regiões do país, atenderam situações de abuso sexual contra criança e adolescente no âmbito do PAEFI. Nota-se que entre as ações e atividades realizadas pelos profissionais que atuam nos CREAS, no PAEFI destacam-se os encaminhamentos: para o CRAS (2.507); para serviços da rede de saúde (2.498); de famílias ou indivíduos para a rede de serviço socioassistencial (2.496); para o Conselho Tutelar (2.483); para órgãos de defesa e responsabilização (2.474); de famílias ou indivíduos para outras políticas públicas (2.463). Os dados demonstram que esse serviço possui institucionalidade nos municípios e os CREAS têm se tornado verdadeiras referências no âmbito local para o atendimento de crianças e adolescentes que sofrem violência sexual. Devido à natureza da política e do PAEFI, esse tem se constituído como articulador da rede de proteção em diversos municípios brasileiros. 
A escola, que também está inserida nessa rede de serviços, deve ter um papel protetivo, atuando em conjunto com outras políticas, pensando em ações diante da ocorrência ou suspeita e prevenindo a violência (FUZIWARA e FÁVERO, 2011; MINISTÉRIO DA SAÙDE, 2010). Existe uma defasagem de dados sobre o trabalho das unidades escolares nas questões referentes à violência sexual de crianças e adolescentes.

Uma das ações que merece destaque na área da educação pelo governo brasileiro é o Projeto Escola que Protege, criado em 2006 pelo Ministério da Educação (MEC). Trata-se de um projeto da Secretaria de Educação Continuada, Alfabetização e Diversidade (SECAD/MEC) que busca formar os educadores de escolas de Ensino Fundamental e Médio de forma que eles sejam capazes de identificar os sinais de violências que os alunos sofrem em seu cotidiano, a fim de encaminhar para os serviços especializados e também de prevenir que a violência aconteça. Outra questão interessante desse projeto é a articulação realizada com as instituições de nível superior, que promovem a formação dos educadores (GUIMARAES et al., 2008).

Apesar dos esforços do programa federal, são poucos os estudos destinados aos seus resultados nas cidades brasileiras. Pedrosa (2012) faz uma análise da implementação do Projeto Escola que Protege na Rede municipal de educação em Fortaleza. Para a autora, a formação continuada, como é disponibilizada no projeto, contribui para incorporação dos temas nas práticas pedagógicas dos profissionais de educação. Como ponto positivo, a autora analisa a possibilidade dos profissionais de realizarem uma intervenção nos casos de violência e encaminhá-los aos órgãos competentes. Como ponto negativo, identifica-se que há uma fragilidade devido à desarticulação dos órgãos que compõe o SGD que muitas vezes não atendem as demandas.

Embora as três políticas mencionadas neste artigo realizem um trabalho importante no que diz respeito ao enfrentamento às violências e componham o Sistema de Garantias de Direitos (SGD), as ações acabam seguindo caminhos próprios e fragmentados, sem que o planejamento e a implementação da política de proteção à criança e ao adolescente se faça de forma integrada. Os documentos normativos reforçam a necessidade de articulação intersetorial, mas não preveem a formulação de ações conjuntas, deixando a cargo dos profissionais do "street level" que organizem formas de articulação, o que as torna pontuais, através de encaminhamentos "de casos", ou limitadas às notificações aos órgãos de vigilância. Incluir o planejamento e execução de ações conjuntas, dividir orçamentos e 
atribuições entre os órgãos e conselhos é tarefa da gestão municipal, com apoio das gestões do estado e federal, de modo a garantir, de fato, a integralidade e a prioridade no atendimento de crianças e adolescentes.

Nosso estudo se limita a levantar essa problemática sem, no entanto, aprofundar respostas e soluções, que precisam ser pensadas, levando-se em consideração as realidades locais e suas particularidades. Porém, sugerimos que esse seja um tema incluído nas agendas das pesquisas destinadas ao tema da violência sexual contra crianças e adolescentes, pois se trata de um fenômeno complexo e que precisa de um conjunto de ações públicas, de responsabilidade do Estado, para a efetivação da proteção social a esse público.

\section{CONSIDERAÇÕES FINAIS}

Diante da discussão apresentada, conclui-se que a violência faz parte da estrutura da sociedade brasileira. Essa violência se materializa de diversas formas, sendo uma delas a violência sexual contra crianças e adolescentes, sua existência evidencia que mesmo com legislações tão avançadas como a Constituição Federal de 1988 e o ECA, o Brasil permanece sendo uma sociedade adultocêntrica e patriarcal na qual mulheres, idosos, crianças e adolescentes são as maiores vitimas de violação de direitos.

As políticas sociais cumprem o papel de garantir o atendimento ao público vulnerável à violência, como é o caso da saúde. Entretanto, elas não conseguem dar conta das várias complexidades referentes à violência sexual, pois as vitimas necessitam de um atendimento integral, abrangendo outras questões que vão além das consequências à saúde das vitimas causadas pela violência.

Neste estudo, foi apresentada uma discussão sobre a necessidade de articulação com o Sistema de Garantia de Direitos (SGD) para assegurar a proteção integral conforme preconiza a legislação e as normativas federais. Evidencia-se que esse SGD tem como finalidade promover, defender e controlar a efetivação integral de todos os direitos para crianças e adolescentes. As ações se materializam a partir dos seus três eixos de defesa dos direitos humanos que possibilitam o acesso a justiça; desenvolvimento da política de 
atendimento dos direitos das crianças e dos adolescentes; controle da efetivação dos direitos humanos através do monitoramento, avaliação e fiscalização das ações públicas; e a promoção e a defesa dos direitos humanos das crianças e adolescentes.

Além das ações no campo da saúde, outras políticas compõem o SGD e são consideradas complementares para o enfrentamento e a prevenção da violência sexual contra crianças e adolescentes. As políticas de saúde, assistência social, e educação, através de seus serviços, programas e projetos têm realizado um trabalho importante, no entanto, as ações são pontuais e fragmentadas, sem uma articulação sistemática entre as mesmas, havendo experiências nos níveis locais, que precisam ser mais bem pesquisadas.

\section{REFERÊNCIAS}

ADORNO, Sérgio. Exclusão socioeconômica e violência urbana. Sociologias, Porto Alegre, n.8, pp.84-135, jul/dez 2002, p.84-135.

ADORNO, Sérgio. A violência na sociedade brasileira: um painel inconclusivo em uma democracia não consolidada. Revista Sociedade e Estado, vol. 10, no 2, jul/dez 1995, p.299-342.

ASSOCIAÇÃO BRASILEIRA MULTIPROFISSIONAL DE PROTEÇÃO À INFÂNCIA E À ADOLESCÊNCIA (ABRAPIA). Abuso Sexual contra crianças e adolescentes: Mitos e Realidades. $3^{\mathrm{a}}$ edição. Petrópolis: Rio de Janeiro, 2002.

AZEVEDO, Maria Amélia; GUERRA, Viviani Nogueira de (Orgs.). Infância e Violência Doméstica: Fronteiras do Conhecimento. $6^{\mathrm{a}}$ Ed., São Paulo, Cortez, 1993.

BASTOS, Elide Rugai. Casa-Grande \& Senzala (Gilberto Freyre). "In":MOTA, Lourenço Dantas (Orgs). Introdução ao Brasil. Um banquete no trópico, 1. São Paulo: Senac, , 1999.

DAHLBERG, Linda L;. KRUG, Etienne G. Violência: um problema global de saúde pública. Ciênc. Saúde Coletiva, vol.11., p.1163-1178, 2007.

DAY, V. P.; TELLES, L.E.B.; ZORATTO, P.H.; AZAMBUJA, M.R.F,; MACHADO, D.A.;SILVEIRA, M.B.; DEBIAGGI, M.; REIS, M.G; CARDOSO, R.G; BLANK, P.. Violência doméstica e suas diferentes manifestações. Rev. Psiquiatria, Rio Grande do Sul, vol.25, p. 9-21, abril/2003.

DESLANDES, Suely Ferreira. Atenção a Crianças e Adolescentes Vítimas de Violência Doméstica: Análise de um Serviço. Cad. de Saúde Pública, Rio de Janeiro, v.10, n.1, p.177-187, 1994.

DESLANDES, Suely Ferreira; GOMES, Romeu. Interdisciplinaridade na saúde pública: um Campo em construção. Ribeirão Preto, Rev. Latino-Am. Enfermagem, vol.2, n.2, p. 103-114, julho 1994.

DESLANDES, Suely Ferreira; VIEIRA, Luiza Jane Eyre de Souza; CAVALCANTI, Ludmila Fontenele; SILVA, Raimunda Magalhães da. Atendimento à saúde de crianças e adolescentes em situação de violência sexual, em quatro capitais brasileiras. Interface, Botucatu, vol.20, n.59, p.865-877, 2016.

FALEIROS, Eva T. Silveira; CAMPOS, Josete de Oliveira. Repensando os Conceitos de Violência, Abuso e Exploração Sexual de Crianças e de Adolescentes. Brasília: UNICEF, 2000. 
FRANCISCHINI, Rosângela; NETO, Manoel Onofre de Souza. Enfrentamento à violência contra crianças e adolescentes: projeto escola que protege. Revista do Departamento de Psicologia - UFF, v.19 - n.1, p.243-252, jan./jun 2007

FUZIWARA, Aurea Satarni; FÁVERA, Eunice Teresinha. A Violência sexual e os direitos da criança e do adolescente. "In:" AZAMBUJA, Maria Regina Fay de; FERREIRA, Maria Helena Mariante [et al], Porto Alegre: Artmed,2011, p.35-47.

GUIMARÃES, Sandra Regina Kirchner; MINDAL, Clara Brener; SILVA, Paulo Vinicius. Escola que protege: muito além da sala de aula. "In:" SILVA, Paulo Vinivius Baptista; LOPES, Jandicleide Evangelista, Carvalho Arianne. Por uma escola que protege: a educação e o enfrentamento à violência contra crianças e adolescentes. Ponta Grossa, Editora UEPG; Curitiba, Cátedra UNESCO de Cultura da Paz UFPR, 2008. P. 11-19

HABIGZANG, Luísa F.; KOLLER; Sílvia H.; AZEVEDO; Gabriela Azen; MACHADO, Paula Xavier. Abuso sexual infantil e dinâmica familiar: aspectos observados em processos jurídicos. Psic. Teor. e Pesq., vol.21, n.3, p.341-348, 2005.

IAMAMOTO, Marilda Villela. O Serviço Social na Contemporaneidade: Trabalho e Formação Profissional. 23. Ed., São Paulo, Cortez, 2012.

JUNQUEIRA, Luciano. A. Prates. Intersetorialidade, transetorialidade e redes sociais na saúde. Revista de Administração Pública, Rio de Janeiro, v.34, n.6, p.35-45, 2000.

LAPA, José Roberto do Amaral. Formação do Brasil contemporâneo (Caio Prado Junior). "In": MOTA, Lourenço Dantas (Orgs). Introdução ao Brasil. Um banquete no trópico, 2. São Paulo: Senac, 1999.

LIMA, Jeanne de Souza; DESLANDES, Suely Ferreira. A notificação compulsória do abuso sexual contra crianças e adolescentes: uma comparação entre os dispositivos americanos e brasileiros. Interface, Botucatu, vol.15, n.38, p.19-832, Julho/Setembro,2011.

MINAYO, Maria Cecília de Souza. Violência e Saúde. 1.Ed., Rio de Janeiro: FIOCRUZ, 2006.

MINAYO, Maria Cecília de Souza. Violência Social sob a Perspectiva da Saúde Pública. Cadernos de Saúde Pública, Rio de Janeiro, v.10, n.1, p. 07-18, 1994.

MINAYO, Maria Cecília de Souza. Violência um Problema para a Saúde dos Brasileiros. "In:" SOUZA. Edinilsa Ramos de; MINAYO. Maria Cecília de Souza (Orgs.). Impacto da violência na saúde dos brasileiros. Brasília: Ministério da Saúde, 2005.

MINISTÉRIO DA SAÚDE. Linha de Cuidados para Atenção Integral à Saúde de Crianças, Adolescentes e suas Famílias em Situação de Violências: Orientações para gestores e profissionais de saúde. Brasília: Ministério da Saúde, 2010.

MINISTÉRIO DA SAÚDE. Prevenção e tratamento dos agravos resultantes da violência sexual contra mulheres e adolescentes: norma técnica. 3a ed., Brasília (DF): Ministério da Saúde, 2012.

MINISTÉRIO DA SAÚDE. Viva: Vigilância de Violências e Acidentes: 2013 e 2014. Brasília: Ministério da Saúde, 2017.

OLIVEIRA, Antonio Carlos. Abuso sexual intrafamiliar de crianças e a família como totalidade. Social em Questão: Rio de Janeiro, Ano XIV, n.28, p.233-262, 2012.

PAIXÃO, Ana Cristina Wanderley da. Abuso Sexual Infantojuvenil: A Atuação da Secretaria Municipal de Saúde e Defesa Civil do Rio de Janeiro para Garantir o Atendimento especializado das Vitimas. Tese (Doutorado em Saúde da Criança e da mulher) Instituto Fernandes Figueira, Rio de Janeiro, RJ, 2011. 
PEDROSA, Verônica Maria Benevides. Projeto escola que protege: uma política pública educacional transversal e interdisciplinar. Artigos Inéditos, 2012, p.100-107.

QUAGLIA, Márcia; MARQUES, Myriam Fonte; PEDEBOS, Geneviève Lopes. O Assistente Social e o Atendimento a Famílias em Situação de Violência Sexual Infantil. "In:" AZAMBUJA. Maria Regina Fay de; FERREIRA. Maria Helena. [et al.]. Violência Sexual Contra Crianças e Adolescentes. Porto Alegre: Artmed, 2011.

RIBEIRO, Márcia Aparecida; FERRIANI, Maria das Graças Carvalho; REIS, Jair Naves. Violência sexual contra Crianças e adolescentes: Características relativas à vitimização nas relações Familiares. Caderno de Saúde Pública, Rio de Janeiro, v.20, n.2, p. 456-464, 2004.

SAFFIOTI. Heleneith Iara Bengiovani. Gênero, Patriarcado, Violência. 1 Ed. São Paulo: Fundação Perseu Abramo, 2004.

SANCHEZ, Raquel Niskier; MINAYO, Maria Cecília de Souza. Violência contra Crianças e Adolescentes: Questão Histórica, Social e de Saúde. "In:” LIMA, Cláudia Araújo (Coord.) et.al. Violência faz mal à saúde. Brasília: Ministério da Saúde, 2006, p.29-38.

SILVA, Maria Amélia da Silva. Violência Contra Crianças-Quebrando o Pacto do Silencio. "In:" FERRARI, C.A; VECINA,Tereza Cristina Cruz; FERRARI, Dalka Chaves de Almeida (Orgs.) O Fim do Silencio na Violência Familiar: Teoria e Prática. São Paulo: Ágora, 2002.31.

VAINFAS, Ronaldo. Capítulos de história colonial (Capistrano de Abreu). "In": MOTA, Lourenço Dantas (Orgs). Introdução ao Brasil. Um banquete no trópico, 2. São Paulo: Senac, 2001.

VELHO, Gilberto. Violência e conflito nas grandes cidades contemporâneas. VII Congresso Luso Afro Brasileiro de Ciências Sociais em Coimbra, 2004. 34.

VELHO, Gilberto. Violência, Reciprocidade e desigualdade: uma perspectiva antropológica. "In:" VELHO, Gilberto; ALVITO, Marcos (Orgs.). Cidadania e violência. Rio de Janeiro, FGV/UFRJ, 2000. 